GA-A24375

\title{
STRUCTURAL RESPONSE OF THE DIII-D TOROIDAL FIELD COIL TO INCREASED LATERAL LOADS \\ by
}

E.E. REIS and E. CHIN 


\section{DISCLAIMER}

This report was prepared as an account of work sponsored by an agency of the United States Government. Neither the United States Government nor any agency thereof, nor any of their employees, makes any warranty, express or implied, or assumes any legal liability or responsibility for the accuracy, completeness, or usefulness of any information, apparatus, product, or process disclosed, or represents that its use would not infringe privately owned rights. Reference herein to any specific commercial product, process, or service by trade name, trademark, manufacturer, or otherwise, does not necessarily constitute or imply its endorsement, recommendation, or favoring by the United States Government or any agency thereof. The views and opinions of authors expressed herein do not necessarily state or reflect those of the United States Government or any agency thereof. 


\title{
STRUCTURAL RESPONSE OF THE DIII-D TOROIDAL FIELD COIL TO INCREASED LATERAL LOADS
}

\author{
by \\ E.E. REIS and E. CHIN
}

This is a preprint of a paper presented at the 20th IEEE/NPSS Symposium on Fusion Engineering, San Diego, California, October 14-17, 2003 and to be published in Fusion Science and Technology.

\author{
Work supported by \\ the U.S. Department of Energy \\ under Contract No. DE-AC03-99ER54463
}




\title{
Structural Response of the DIII-D Toroidal Field Coil to Increased Lateral Loads
}

\author{
E.E. Reis and E. Chin \\ General Atomics, P.O. Box 85608, San Diego, California 92186-5608
}

\begin{abstract}
Recent calibration shots in which full toroidal field (TF) coil current interacted with the maximum poloidal field coils have produced increased lateral loads on the outer sections of the TF-coil. The increased lateral loads have resulted in deflections that have been sufficient to cause the TF-coil to contact adjacent equipment and produce a transient short to ground within the coil. The six outer turns of each TF-coil bundle are clamped together by insulated preloaded studs to provide increased bending stiffness. These sections of the outer bundles depend on friction to react the lateral loads as a bundle rather than six individual turns. A major concern is that the increased loads will produce slip between turns resulting in excessive lateral deflections and possible damage to the insulating sleeve on the preloaded studs.
\end{abstract}

A finite element structural model of the TF-coil was developed for the calculation of deflections and the shear load distribution throughout the coil for the applied lateral loads from a full current calibration shot. The purpose of the updated structural model is to correlate the applied lateral loads to the total shear force between the unbonded sections of the outer turns. An allowable integrated lateral load applied to the outer turns is established based on the maximum shear force that can be reacted by friction. A program that calculates the magnetic fields and integrated lateral load along the outer turns can be incorporated into the plasma control system. The integrated load can then be compared to the calculated allowable value prior to execution of calibration shots. Calibration shots with a calculated total lateral load greater than the allowable value will be prevented.

\section{INTRODUCTION}

The TF-coil consists of $144 \mathrm{D}$-shaped turns as shown in Fig. 1. The straight sections of these turns are bonded together to form a solid cylindrical centerpost that is an effective structure in reacting torsion loads. The outer sections of each turn are gathered together into 24 bundles of six turns. The middle section of an outer bundle is bonded to form a structure that is 36 times stiffer to lateral bending loads than six individual turns. The ends of the outer bundles are not bonded so that the in-plane flexibility of each turn can provide good electrical contact at the bolted scarf joints (Fig. 1). The unbonded sections of the outer bundles are then clamped together with high strength studs. The clamping provides a friction interface between turns to develop the same bending stiffness as the bonded section.

The high strength studs clamping the outer turns utilize special washers shown in Fig. 2 and described in Ref. [1]. These washers allow the gap between the insulating sleeve and the hole to be injected with epoxy. In the event that friction forces between the outer turns exceed the capability achieved by clamping, the epoxy impregnated studs will act as shear pins. Although the epoxy insulated stud design was tested in double shear to $10^{5}$ pounds $\left(4.45 \times 10^{5} \mathrm{~N}\right)$ without major damage, it is not desirable to utilize the shear pin capability of the stud.

Lateral loads are applied to the TF-coil as a result of the current in the coil passing through the normal component of the poloidal fields of the other coil systems. The centerpost of the coil reacts some of the lateral loads through its torsional stiffness. Wedges between TF-coil bundles transfer the lateral loads applied to the outer turns to the anti-torque structure shown in Fig. 3. The wedges are designed to provide a zero tolerance interface with the 24 bundles of the TF-coil as described in Ref. [2]. In addition to minimizing coil deflections, the anti-torque structural system also reduces the alternating stress range in the fingerjoint of the coil.

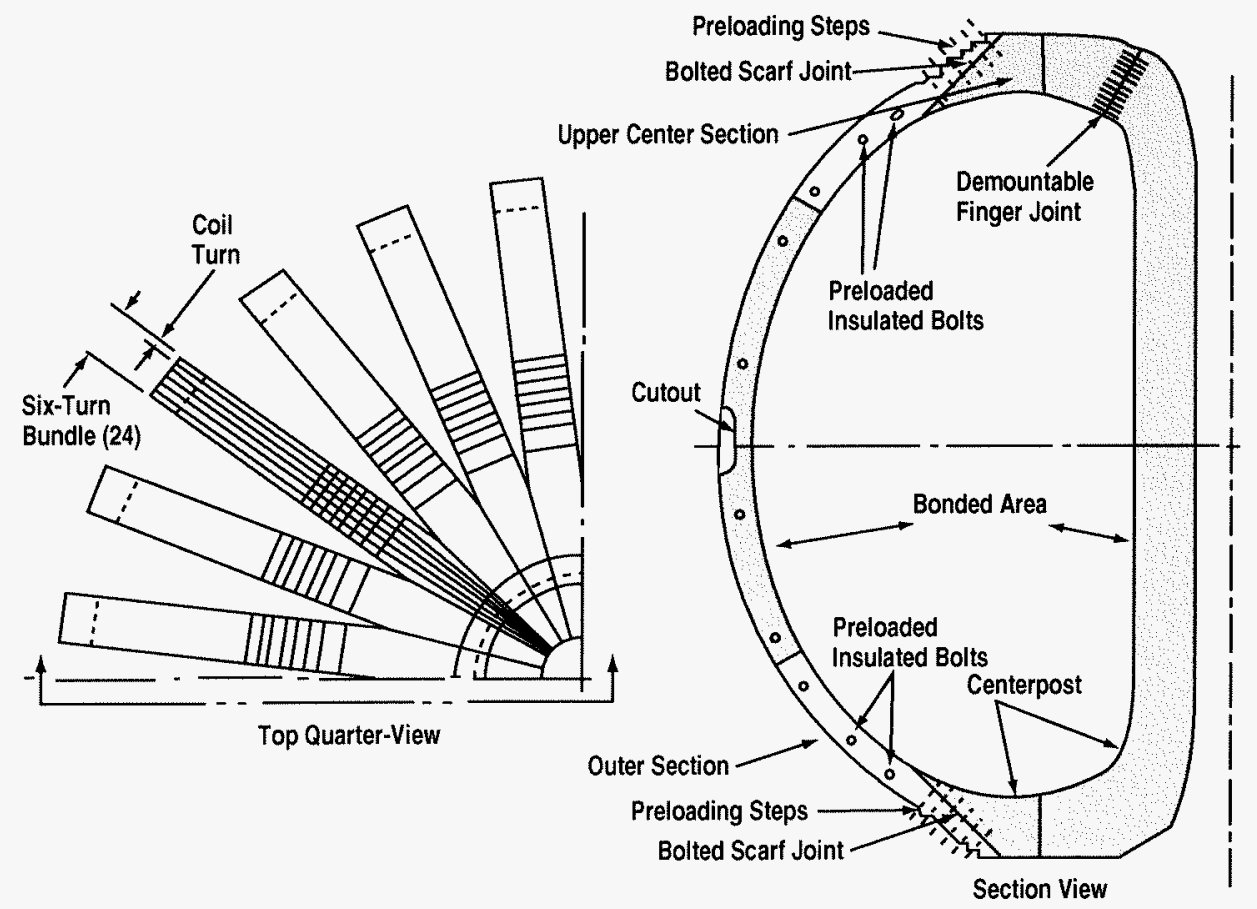

Fig. 1. Bonded sections of the TF-coil. 


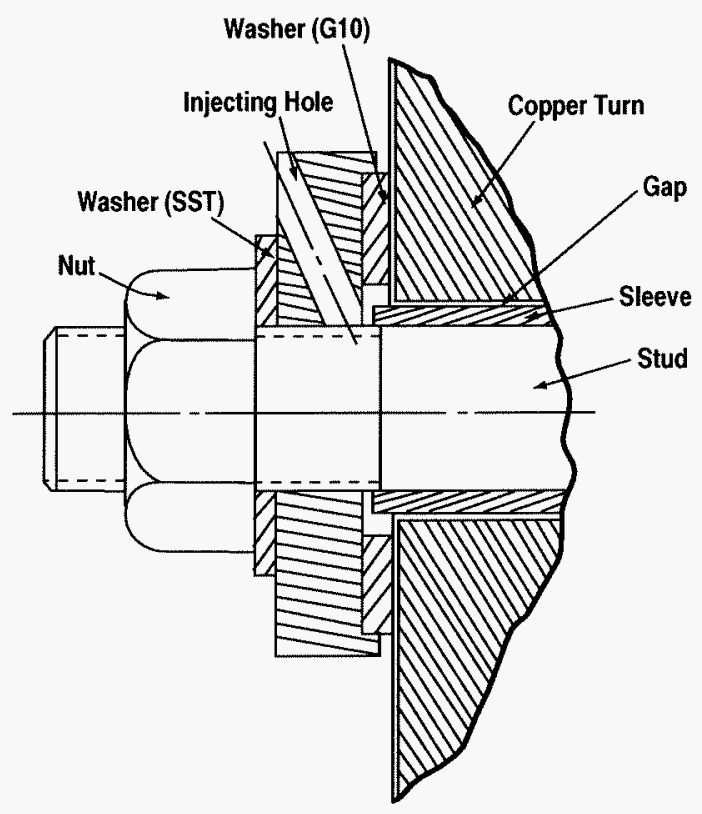

Fig. 2. Insulated shear bolt clamping hardware.

Calibration shots with full current in the coil system and zero plasma current are occasionally requested to load test new components, such as the internal correction coils [3], or to calibrate new diagnostics. To prevent excessive deflections and possible slip between turns of the TF-coil for calibration shots, the plasma control system (PCS) can be updated to include a program that calculates the integrated lateral load over the outer turns between the horizontal mid-plane and the wedge locations shown in Fig. 3. The PCS could than perform a comparison of the total lateral load on the outer bundles to a calculated allowable value prior to execution of full power calibration shots.

The lateral displacements of all 24 outer bundles of the TF-coil are measured during a shot by linear motion transducers. The maximum expected lateral displacement at the upper section of the outer bundles is \pm 0.25 in. [1]. However, calibration shot 111031 produced a lateral deflection of the outer bundles that resulted in a ground fault of the TF-coil. Although no deflection data was taken for this shot, it is presumed that the outer bundle elastically deflected to hit some adjacent equipment that locally penetrated its insulation.

The maximum shear force between turns of the unbonded sections determines the allowable lateral load in the outer bundles that the insulated shear studs can react by friction. Also, it is desirable to know the estimated lateral deflections of the TF-coil prior to executing certain high current calibration shots. Therefore, a structural model of the TF-coil subjected to maximum lateral loads for a specified calibration shot was developed and analyzed to correlate the shear force in the unbonded sections to the total applied loads on the outer turns. This establishes the allowable integrated lateral load input to the PCS for determining the acceptability of executing high current calibration shots.

\section{STRUCTURAL MODEL}

A structural model of the TF-coil was developed for input to the COSMOS/M finite element code [4]. The structural model of the TF-coil shown in Fig. 4 consists of beam and spring elements. The structural model represents one bundle of the TF-coil with a centerpost stiffness equal to $1 / 24$ th of the composite cylinder. Boundary conditions are applied to the centerpost so that only rotation about the vertical axis is permitted. Rigid beam members are used to connect the centerline of the centerpost to the finger joint and lower center section. Beam elements with varying cross-sectional properties are used to represent the center and outer sections of one bundle of the TF-coil. Axial and rotational spring elements are used to model the stiffness of the anti-torque frame and the support structure of the coil. The stiffness constants input for the spring elements are given in Fig. 4. The stiffness constants

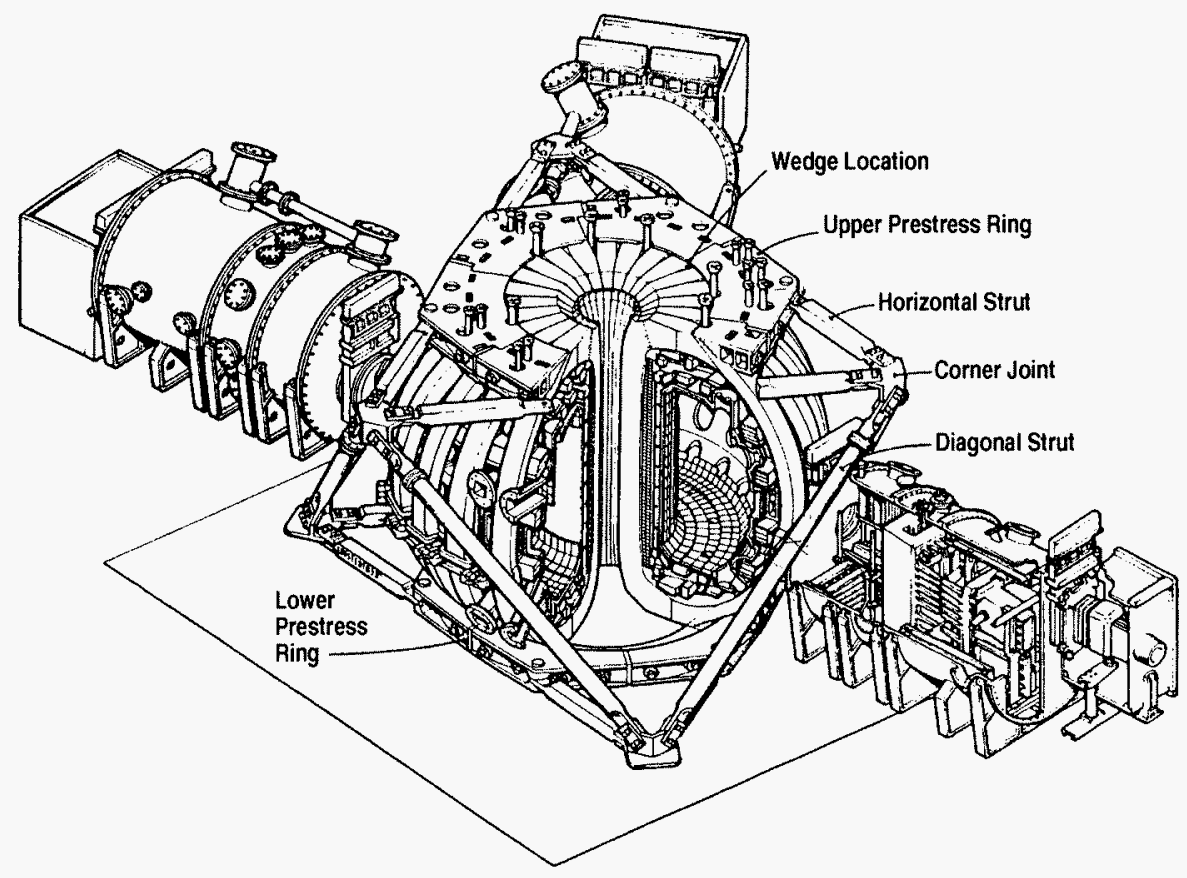

Fig. 3. Isometric view of DIII-D indicating anti-torque structure elements. 


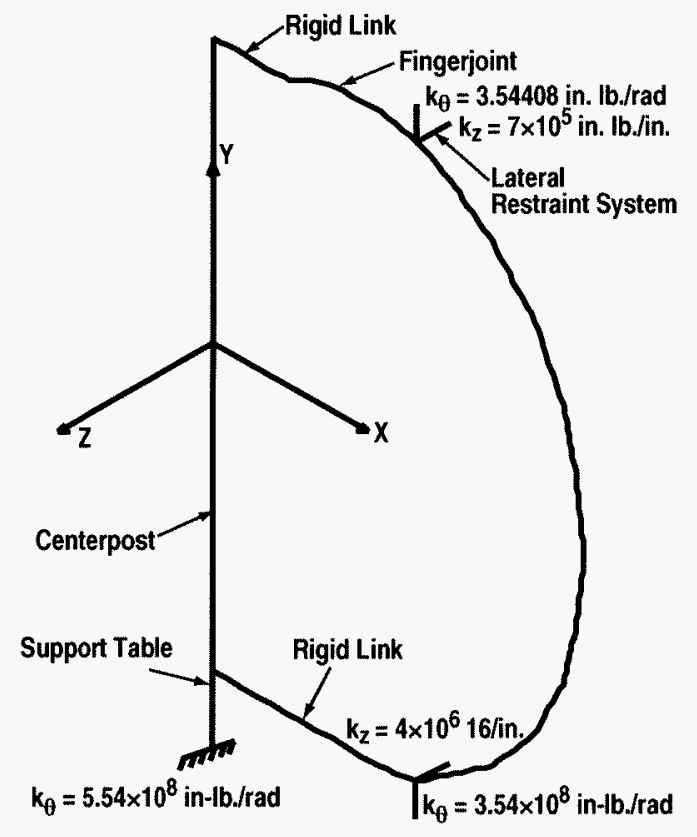

Fig. 4. TF-coil structural model.

for the upper and lower anti-torque frame and the support table were calculated using separate structural model described in Ref. [5]. The calculated values have been adjusted to provide reasonably good agreement between the calculated coil deflections and those measured during start-up tests in 1986.

The lateral load distribution along the length of a TF-coil bundle for calibration shot 111031 is shown in Fig. 5. Although the lateral loads are symmetrical about the machine mid-plane, the TF-coil and its support structures are not. This necessitates developing a structural model of the full TF-coil as shown in Fig. 4. The lateral loads acting as the centerpost are multiplied by the radius to the center of gravity of the trapezoidal shaped bundles and are applied as external torsional loads. The lateral loads on the outer sections of the TF-coil are applied to the structural model as distributed line loads on the beam elements.

The shear flow over a distance of $32.0 \mathrm{in} .(0.81 \mathrm{~m})$ of the two unbonded sections of the outer bundles must be reacted through friction at each end of a bundle by the two preloaded insulated studs. The four high strength studs per bundle are made of a high strength alloy material, MP 159, and each is preloaded to $125,000 \mathrm{lb}\left(5.56 \times 10^{5} \mathrm{~N}\right)$. The average of measured test values for the coefficient of friction between individual turns is 0.43 . Therefore, the maximum allowable shear load over the unbonded sections that reacts the slip force is $107,500 \mathrm{lb}\left(4.78 \times 10^{5} \mathrm{~N}\right)$. However, the coefficient of friction between turns has probably increased due to being highly clamped together over the past eighteen years. This allowable shear load is therefore most likely a conservative value.

As an additional factor of safety, the high strength studs in the unbonded section were installed as insulated shear studs. In the event that the friction forces between turns are exceeded, the stud will carry the shear loads. This design, described in Ref. [1], is based on injecting a hiht strength epoxy, the gap between the G-10 insulating sleeve and hole after the studs are preloaded. Tests on the epoxy filled

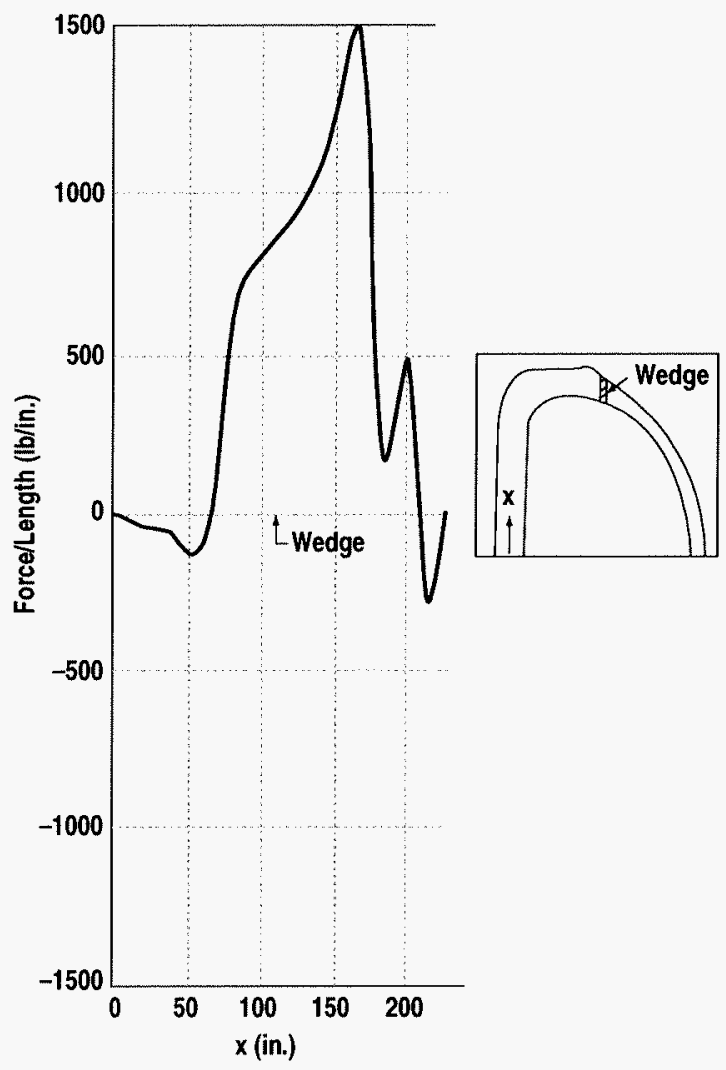

Fig. 5. Lateral force distribution along centerline of TF-coil for Shot 111031

insulating sleeve in double shear showed only slight damage after being loaded to $10^{5} \mathrm{lb}\left(4.45 \times 10^{5} \mathrm{~N}\right)$ in double shear.

\section{STRUCTURAL ANALYSIS RESULTS}

The structural response of the TF-coil to the lateral loads imposed by calibration shot 111031 was calculated for two conditions. The first condition was based on the outer bundle acting as a fully bonded structure without slip occurring between turns. The second case calculated the increased lateral deflection if slip were to occur between a $32.0 \mathrm{in}$. length of the unbonded top and bottom sections of the outer bundle.

The deformed shape and maximum deflection results expected for shot 111031 with no slip between turns is shown in Fig. 6. The maximum lateral deflection is 0.164 in. $(0.42 \mathrm{~cm})$ occurring $55.3 \mathrm{in}$. $(1.4 \mathrm{~m})$ above mid-plane. This is less than the $\pm 0.25 \mathrm{in}$. $(0.64 \mathrm{~cm})$ maximum anticipated deflection of off-center $5 \mathrm{MA}$ plasma shots reported in Ref. [1]. The calculated angle of twist at the top of the centerpost is $5.2 \times 10^{-4}$ radians and the corresponding nominal torsional shear stress in the centerpost adhesive is only 345 psi (2.4 Mpa). The peak shear stress in the centerpost at the fingerjoint interface was calculated to be $1900 \mathrm{psi}(13.1 \mathrm{Mpa})$ in the original structural analysis (Ref. [1]).

The slip load, F, over the 32.0 inch of section that the high strength studs are expected to react is calculated to be $134,600 \mathrm{lb}\left(6.0 \times 10^{5} \mathrm{~N}\right)$. This is greater than the allowable value of $107,500 \mathrm{lb}\left(4.78 \times 10^{5} \mathrm{~N}\right)$, indicating that slip between turns would occur for this shot if not for the epoxy filled insulated studs. 


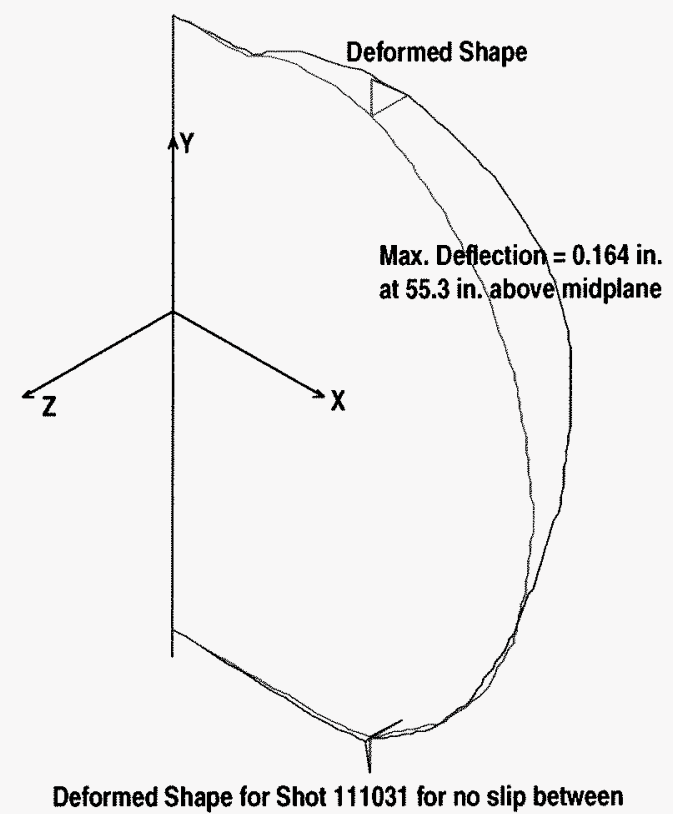

Fig. 6. Deformed shape for Shot 111031 for no slip between outer turns.

To account for slip occurring between the unbonded sections of the upper and lower bundles, the moment of inertia assigned to these elements was reduced by a factor of 36 . The maximum lateral deflection for this condition is increased by a factor of 2.14 over the non-slip condition. The angle of twist of the upper centerpost also is increased, presumably due to additional lateral load being transferred to the anti-torque wedges by the reduced stiffness of the outer bundle.

The peak lateral loads for 5 MA plasma operation described in Ref. [1] are positioned over the upper and lower center sections of the TF-coil. The increased lateral deflections during the test calibration shots were due to the shift in the maxiumum out-of-plane loads toward the mid-plane of the coil. It is concluded that the preloaded insulated bolts were effective in preventing slip between turns of the TF-coil bundles during these test shots. The lateral deflrctions of all twenty-four bundles of the coil are presently being measured during all operation and calibration shots.

\section{PROPOSED LATERAL LOAD LIMIT}

In order to prevent the execution of calibration shots that could result in excessive deflection, it is proposed that the total load on the outer bundle between midplane and the anti-torque wedges be calculated in advance for a proposed set of coil currents. A modified version of the GA code, EFIT, for calculating magnetic field from coil systems can quickly determine the total lateral load for non-plasma shots. The integrated lateral load on the upper outer bundle for shot 111031 was $74,200 \mathrm{lb}$. This produced a slip force between turns of $134,600 \mathrm{lb}$ and is $25 \%$ higher than the maximum allowable value $(107,500 \mathrm{lb})$. Therefore, the maximum integrated lateral load limit for asymmetrical calibration shots is determined to be $59,400 \mathrm{lb}$. It is proposed that the EFIT code be interfaced the PCS so that it can then verify that the integrated lateral load is less than the limit load before executing calibration shots.

For calibration shots that produce lateral loads that are symmetrical about the midplane, the lateral deflection will be checked at less than full power before proceeding to full currents. Lateral deflections of the outer bundle at or near midplane should be limited to \pm 0.25 in. to prevent contact between the TF coil and adjacent equipment.

\section{ACKNOWLEDGMENT}

Work supported by U.S. Department of Energy under Contract DE-AC03-99ER54463.

\section{REFERENCES}

[1] E.E. Reis, et al., "Modifications to the toroidal field coils for DIII-D," Proc. of the 11th Symp. on Fusion Engineering, Austin, Texas, Vol. 1, 271, (1985).

[2] L.G. Davis and F.A. Puhn, "Doublet III anti-torque structure," Proc. of the 6th Symp. on Engineering Problems of Fusion Research, San Diego, California, 635, (1975).

[3] P.M. Anderson, et al., "Design, fabrication and installation of in-vessel control coils for DIII-D," Proc. of the 22nd Symp. on Fusion Technology, Helsinki, Finland, (2002).

[4] COSMOS/M Code, Structural Research and Analysis Corp., Santa Monica, CA, Vol. 2.7, March, 2002.

[5] E.E. Reis, et al., "Stress analysis of Doublet III toroidal coil," Proc. of the 6th Symp. on Engineering Problems of Fusion Research, San Diego, California, 618, (1975). 